\title{
ENTRE EL CASTELLANO MEDIEVAL Y EL ESPAÑOL CLÁSICO: EL CASO DE LA DESCRIPCIÓN Y COSMOGRAFÍA DE ESPAÑA (O ITINERARIO) DE HERNANDO COLÓN
}

\author{
José Javier Rodríguez Toro
}

\begin{abstract}
The Descripción y cosmografía de España -also denominated Itinerario- is considered to be one of the most important research designed by Hernando Colón. The language of this scientific work, in relation to the Spanish period named "de Nebrija" (R. Menéndez Pidal) or "preclásico" (R. Lapesa), is analyzed in our study.
\end{abstract}

0 . En historia de la lengua, como en cualquier disciplina científica, no es infrecuente que con el paso de los años se maticen o, incluso, se rectifiquen "verdades" que en un momento anterior los investigadores consideraban inamovibles. Una de las causas que provocan el replanteamiento de principios generalmente admitidos es la consideración de documentos no tenidos en cuenta hasta la fecha ${ }^{1}$.

Si bien lo que venimos afirmando es consustancial al "adecuado" progreso de la ciencia, ello no quita que en determinadas ocasiones el análisis de esos documentos confirmen, antes al contrario, las opiniones preestablecidas. Así ocurre en el caso concreto que nos ocupa: el resultado del estudio de la Descripción y cosmografía de España o Itinerario de Hernando Colón demuestra la idoneidad de los rasgos lingüísticos propuestos para el período intermedio entre el castellano medieval y el español clásico.

1. Aunque con distintas denominaciones, R. Menéndez Pidal y R. Lapesa coincidían en la consideración de una época histórico-lingüística intermedia entre el castellano medieval y el español clásico. Admitiendo dicha periodización ${ }^{2}$, la Descripción... o Itinerario de Hernando Colón estaría situada en la "época de Nebrija" (Menéndez Pidal 1978: 48-62) o en el "español preclásico" (Lapesa 1986: 274-290), período éste comúnmente calificado

\footnotetext{
${ }^{1}$ Pueden citarse como ejemplos recientes de estas "revisiones" los trabajos de M. Ariza (1998) o R. Cano (1998).

${ }^{2}$ Es bien conocido, con todo, cómo Eberenz (1991: 104-106) propone para la historia del español -de manera análoga a lo que se hace en la de otras lenguas como el francés, el inglés o el alemán- un período intermedio mucho más amplio desde 1450 a 1650- en el que se dieron todas las modificaciones, ya que "el año 1500 no constituye una verdadera frontera en la trayectoria interna del castellano" (Eberenz 1991: 101).
} 
por los autores como de transición en relación con dos aspectos bien distintos que someramente pasamos a presentar.

1.1. En primer lugar, dicha etiqueta alude al abandono casi total de los "excesos" cometidos durante el siglo XV en la entrada de elementos lingüísticos clásicos. Según R. Cano, en los años finales del siglo "los rasgos más hirientes (a nuestra sensibilidad) del XV se suavizan, o incluso desaparecen y se puede ver ya cómo se va configurando la lengua clásica" (1993: 183). Los humanistas proponen entonces un profundo aprendizaje de la lengua latina, de manera que los latinismos sean más razonablemente asimilados. Todo este proceso que comentamos podría resumirse con las siguientes palabras de Lapesa (1986: 274): "A la admiración extremosa -a veces superficial- por el mundo grecolatino sucede el afán de conocimiento verdadero".

En la lengua literaria se comprueba fácilmente dicha transición al comparar la obra de autores latinizantes como Juan de Mena con la de autores más "sencillos" como Jorge Manrique o Fernando de Rojas. De este modo, según R. Lapesa, en la Celestina "los rasgos no se prodigan con tanta cargazón pedantesca como en los prosistas de la época anterior, y el hipérbaton no existe casi" (1986: 277).

Así las cosas, Hernando Colón sería un hombre prototípico de esta transición como resultado de la completa formación que había recibido en la Corte de los Reyes Católicos (1493-1502) bajo la tutela de Pedro Mártir de Anglería (Guillén 1992): el ansia por dominar los más variados saberes, su conocido amor por los libros, el dominio del latín (casi la totalidad de sus manuscritos está escrita en esta lengua) o el conocimiento de los hábitos escriturarios humanísticos constituyen buena prueba de ello.

1.2. El término transición, por otra parte, también se ha empleado para referirse a los cambios lingüísticos que determinan el paso del castellano medieval al español clásico.

Ahora bien, el tratamiento que a estos cambios han dedicado los filólogos no se puede calificar por menos que de irregular. Así, en contraste con las tantas veces estudiadas alteraciones en el plano fónico (vid. 1.2.1.), el análisis de los cambios morfológicos o sintácticos (vid. 1.2.2.) ha sido pocas veces abordado en opinión de R. Cano (1993: 184) o E. Ridruejo (1994).

1.2.1. Se acepta que se venían produciendo en la modalidad castellanovieja, al menos, desde fines del XIV la pérdida de la aspiración procedente de la F- inicial latina (conservada entonces en toda la zona al sur de Madrid) y las desfonologizaciones de la oposición oclusiva / fricativa entre las consonantes labiales sonoras y de la oposición sorda / sonora en las sibilantes (Alarcos 1986 y 1988).

Como bien sabemos, aunque se haya propuesto al sustrato vasco como "causa" de los fenómenos citados (Martinet 1974: 450-451), las razones que los han provocado, en especial las desfonologizaciones referidas, son de índole estructural: el escaso rendimiento funcional de las oposiciones determinaron su desaparición (Alarcos 1986 y 1988; Ariza 1990 y 1994). 
Las alteraciones nacidas en Castilla la Vieja pasarán durante el Siglo de Oro a ser características de la nueva pronunciación del castellano en sustitución de la "norma" toledana. Alarcos defendía que no fue "una repentina mutación fonética, sino más bien la prolongación geográfica y social de fenómenos que ya se daban en hablas peninsulares en los siglos anteriores" (1988: 48).

Simultáneamente, la sustitución de las sibilantes apicoalveolares por las dentales una vez que éstas habían perdido su oclusión y de africadas se convirtieron en fricativas, era un fenómeno originario de Andalucía Occidental -con centro en la, ya por entonces, floreciente ciudad de Sevilla- que comenzaba a difundirse por los territorios anexionados a la Corona de Castilla en aquellos mismos años: el Reino de Granada, las Islas Canarias y América en cuyas repoblaciones el contingente de andaluces era el más numeroso.

1.2.2. Entre las modificaciones morfosintácticas, cabe citar (vid. además Lapesa 1986: 393-408):

-La gramaticalización de haber que, de verbo transitivo para expresar la posesión en concurrencia con tener, se convierte en el auxiliar de los tiempos compuestos de todos los verbos, papel compartido en lo antiguo con ser que pasa a especializarse en la pasiva.

-La forma en - $r a$ abandona su situación etimológica en el modo indicativo para pasar al subjuntivo.

-Retroceso de ser a favor de estar para la expresión locativa.

-No encontramos ya el artículo determinado ante el posesivo, salvo en niveles populares.

-La impersonalidad pasa a expresarse por medio de giros pronominales.

Según Ridruejo (1994: 53), aunque estos cambios no se produjeran a la vez, sí que "parecen triunfar claramente en un reducido intervalo temporal, esto es, desde la segunda mitad del siglo XV al primer tercio del XVI".

Cano (1993: 184-185) por su parte, cree que la simplificación estructural del sistema castellano tenía como objetivo la consecución de "un instrumento lingüístico más cómodo de manejar, menos cargado de elementos poco funcionales". Este autor estima oportuna la distinción entre fenómenos de "confluencia" y de "diferenciación". Entre los primeros cita la práctica desaparición de yacer o fincar como verbos atributivos (desde entonces restringidos a ser / estar), de los anafóricos y (<IBI) y ende, de la preposición so y de las conjunciones ca, maguer... Además, dejan de emplearse las construcciones partitivas dependientes directamente del verbo. Un fenómeno de diferenciación de la época es la aparición de la preposición a ante el sintagma nominal que acompaña a un verbo con pronombre se ocasionándose el paso de una estructura mediopasiva a una plenamente impersonal.

1.3. Todo este proceso de "aligeramiento" intrasistemático que está experimentando la lengua coincide en el tiempo con su expansión geográfica y social dentro y fuera de la Península: 
-Ya en época medieval habían sido asimilados por el castellano los "dialectos históricos" (¿o habían confluido los tres en una lengua unitaria?), proceso que afecta también al romance navarro aunque desde principios del XVI porque es entonces cuando se incorporó a la corona castellana. Además, en ese siglo algunos de los principales autores portugueses y catalanes adoptan el castellano en su producción literaria.

-Por otro lado, el español va camino de convertirse en la lengua más utilizada en Europa por la influyente presencia política, militar y cultural de sus hablantes (García Blanco 1958: 53-54; cfr. la conocida anécdota protagonizada por Carlos V en Menéndez Pidal 1978: 66). No es menos importante, como sabemos, el inicio de su expansión por el Nuevo Mundo.

2. Llegados a este punto, pasamos a considerar los resultados del análisis lingüístico realizado a la Descripción... o Itinerario en relación con la época de la historia del español en la que se encuentra situada.

Es indudable que Hernando Colón (Córdoba, 1488-Sevilla, 1539), el hijo menor del descubridor de América, es más conocido por su bibliofilia -poseyó la colección particular de libros más importante de la primera mitad del siglo XVI (Wagner 1992)- que por su inacabado proyecto de descripción geográfica de la península Ibérica. Éste fue un trabajo en equipo bajo su coordinación que tenía como objetivo último la confección de un completo diccionario de topónimos en el cual a todas las poblaciones, ordenadas alfabéticamente, se les dedicaría como mínimo un folio donde figuraran su número de habitantes, el tipo de poblamiento, la identidad del propietario en el caso de que lo tuviera, las distancias a los lugares más próximos, así como las características del terreno que atravesaban los caminos para llegar a ellos.

Comenzado en agosto de 1517, las razones por las que la realización de la Descripción... o Itinerario se detuvo seis años más tarde están rodeadas del más absoluto misterio: se cree que el Consejo de Castilla no entendió que una empresa de esta magnitud estuviera en manos de un particular, aunque Hernando Colón fuera un reputado cosmógrafo y hombre de confianza de Carlos V. El que Hernando Colón formara parte del séquito que lo acompañó a su coronación como emperador en Aquisgrán demuestra la alta consideración en que era tenido nuestro hombre.

Los dos gruesos códices que de la obra se conservan en la Biblioteca Colombina de Sevilla se corresponden con lo que hubieron de ser las dos fases de elaboración que tuvo la empresa: el primero -signatura 10-1-2- está constituido por los cuadernos en que los emisarios hernandinos anotaban las descripciones de las zonas por las que pasaban. En el segundo de los volúmenes -signatura 10-1d-3- el mismo Hernando Colón comenzó a extractar y ordenar por localidad los datos recogidos en el "trabajo de campo". Así como este volumen representaría el resultado final en forma de diccionario de topónimos, el primero es una creación facticia posterior a la muerte de Hernando Colón para evitar que se extraviaran los cuadernos. Prueba de esta circunstancia es la aparición de dos de los cuadernos, bajo la signatura 7855, en la Biblioteca Nacional de Madrid (Marín 1970: 161251). 
2.1. Como se redactó en un período de transición (vid. 1.2.) pueden observarse en sus páginas múltiples alternancias entre formas antiguas, ocasionalmente más numerosas, que acabarán siendo desechadas por el sistema, y modernas. La Descripción... o Itinerario ofrece, en este particular, la vívida fotografía de una lengua en crisis $^{3}$.

2.1.1. Nivel fónico (vocalismo): hemos extraído voces que mantienen el vocalismo átono habitual en los textos de la Edad Media: bevir (44A), devisan (76vA, 538rA, 51vC, $53 \mathrm{vC})$, cuatro casos de edeficio $(507 \mathrm{rA}, 509 \mathrm{vA}, 510 \mathrm{vA}, 523 \mathrm{vA})$ por un único ejemplo de edificio (181B, por tanto obra de Hernando Colón), eglesia (31A) escrito por el propio Hernando Colón a renglón seguido de la forma moderna iglesia (31A), encorporada (350rA, 530vA), mesmo (24vA, 33A, 35A, 39A, 40rA, 22C) --más frecuente que mismo (67rA, 163rA, 438vA, 486vA, 487vA, 558rA, 598vA, 670vA, 22C)-- también preferido aquél por el menor de los Colón, monesterio (14rA, 55A, 56vA, 91rA, 97vA, 184vA, $185 \mathrm{vA}, 188 \mathrm{vA}, 222 \mathrm{vA}, 404 \mathrm{vA}, 407 \mathrm{vA}, 427 \mathrm{vA}, 536 \mathrm{vA}, 553 \mathrm{rA}, 339 \mathrm{~B})$ frente a monasterio (10vA, 18vA) y renconada (101rA, 117vA, 142rA, 185rA, 188rA, 467vA). Además, sotil (31A), logares (24C) frente a lugares (24C) y sojeta (523vA, 542rA) (Corominas-Pascual, Ss.vv.).

Por otra parte, encontramos aún conservada la $e$ final del latino FIDE (CorominasPascual, s.v. fe) en los siguientes topónimos: la fee (142rA, 279vA), santa fee (226vA, 227vA, 228vA, 230rA, 305rA, 42vC) junto a dos casos de santa fe (227rA, 295vA), y santyago de fee (288v). Por analogía, la $e$ duplicada se da también en nombres donde no corresponde etimológicamente: atarafee $(226 \mathrm{v}, 43 \mathrm{C}, 43 \mathrm{vC})$ frente a atarafe $(43 \mathrm{vC})$, axarafee (283vA) frente a axarafe (282vA) y xetafee (252r, 328r) .

Nivel fónico (consonantismo):

$1^{\circ}$.- El ensordecimiento de los fonemas sibilantes sonoros y la confluencia de éstos con sus pares sordos es el fenómeno de mayores repercusiones gráficas en nuestra obra. Así, por ejemplo, de las dentales africadas tenemos alternancias del tipo de las siguientes: algeçilla (540vA) / algezilla (538vA), algeçira (279rA) / algezira (47A), boyeçillo (368rA) / boyezillo (4A), breçales (598rA, 598vA, 602vA) / brezales $(602 \mathrm{rA}, 602 \mathrm{vA})$, carrionçillo (246rA, 247rA, 248rA, 276rA) / carrionzillo (241rA, 244bis rA, 318rA), chuçena (197vA, 284rA, 83vC) / chuzena (197rA, 200vA), duçe (566rA) / duze (665vA), ençinares (171rA) / enzinares (162vA, 163rA, 432rA, 480vA...), galiçia (590rA) / galizia (589vA), laçaros, los (420vA) / lazaros, los (421vA, 195B) y mançera (104vA, 118vA, 377rA, 384rA, 414vA) / manzera (19A).

De las apicoalveolares hemos seleccionado: barrancosa (37C, 38C) / barrancossa (672rA, 677rA, 49vC), casas de don millan, las (182rA) / cassas de don millan, las (183vA), casas de don pedro, las (445vA) / cassas de don pedro, las (442rA, 443vA,

\footnotetext{
${ }^{3}$ En la transcripción de los ejemplos del original considerados a partir de este punto, hemos optado por no añadir ni tildes ni signos de puntuación conforme a las normas actuales; tampoco empleamos mayúsculas para los nombres propios. Entre paréntesis se adjunta el número de folio, si es recto o vuelto, y las letras $\mathrm{A}, \mathrm{B}$, o $\mathrm{C}$ en referencia a los códices 10-1-2 y 10-1d-3 y el manuscrito 7855, respectivamente.
} 
448vA), casar de caçeres, el (182rA) / cassar de caçeres, el (182vA), çespedoșa (602vA) / çespedossa (602vA), dificultossa (37C), espesos (202rA, 443vA, 457rA) / espessos (432rA, 41C), espinosa (607rA) / espinossa (607rA), teso (624vA) / tesso (618rA, 620rA, 620vA, $622 \mathrm{rA})$, travieso (208rA, 528vA, 655vA) / traviesso (648vA) y viso, el (621rA, 621vA) / visso, el (620vA), entre otros.

Ahora bien, los más abundantes son los que denuncian la desfonologización de la oposición sorda-sonora entre las prepalatales fricativas, lo cual probaría la extraordinaria difusión que en los primeros años del siglo XVI tiene un cambio ya documentado en el XV (Ariza 1993: 20, Ariza 1994: 233, Ariza 1996: 57-58): abenoja (317rA, 321rA) / abenoxa (315vA), ajofrin (249rA, 251vA) / axofrin (124rA), alguijuela (212vA, 243B) / alguixuela (159rA, 212rA, 243B), aljarafee (197vA) / axarafe, el (202rA, 203vA, 207rA, 83B), guadalajara (517vA, 518vA) / guadalaxara (516rA), guijas alvas (353rA, 353vA, 354rA, 355rA) / guixas alvas (69vA, 352rA, 354vA), guijo, el (391vA, 394rA, 264B) / guixo, el (176rA, 312vA, 392vA, 394rA), jodar (242vA, 22vC) / xodar (237vA, 512rA), jumilla (320vA) / xumilla (662vA, 669rA), juncares (660vA) / xuncares (660vA), marmolejo (471rA, 472vA) / marmolexo (473rA), peñatajada (128rA, 231rA) / peñataxada (233vA), realejo (185rA, 224rA) / realexo (223vA), y tejada (83B, 83vB) / texada (203rA, 286vA), entre otros muchos.

Frente a todos los ejemplos anteriormente aducidos, no tienen el mismo valor probatorio las palabras que presentan en su cuerpo fónico dos sibilantes. La presencia de dos sonidos tan próximos articulatoriamente puede condicionar directamente el trueque gráfico, puesto que no es descartable el hecho de que actúen procesos disimilatorios o asimilatorios: bejijar (313vA) / bexixar (239vA) / bejixar (21vC), çaragoça (1A, 558vA, 619rA) / zaragoça (338vA), çarçosa (25vA) / çarzosa (24v), çerezeda (342vA) / zerezeda (338rA, 348rA), gajanejos (582vA, 583rA, 583vA) / gaxanejos (580vA), rexugena (205rA) / rexuxena (205rA), xujar (260rA, 261rA, 262rA, 263rA) / xuxar (261rA, 445vA, 454rA).

$2^{\circ}$.- Los cambios gráficos debidos a la neutralización de las sibilantes dentoalveolares y las apicoalveolares en favor de las primeras, esto es, el fenómeno de seseo-ceceo, no son nada frecuentes en el manuscrito: ¿demostraría que ni los redactores en colaboración con Hernando Colón ni él mismo por ser hablantes presumiblemente cultos participaban de un fenómeno fonético tan característico de la Andalucía Occidental de fines del siglo XV y principios del XVI (Ariza 1994: 226-231)? No deben tenerse en cuenta aquellos casos que presentan en su mismo cuerpo fónico otra sibilante dental o alveolar con lo que originan alguna asimilación o disimilación sea gráfica, sea fonética (Ariza 1997: 130) del tipo çauzedosa (160vA) / sauzedoso (387vA, 435rA), çiguença (516rA, 540rA, 541vA, 545rA, 548rA, 612rA) / siguença (546rA) - oyguença (546rA), plazençia (375vA, 589rA) o plazençuela $(211 \mathrm{rA})$ ni cuando la neutralización de estas sibilantes se produce en posición implosiva ya que esto reflejaría, más bien, el proceso previo de fricatización de la dental: asnalcaçar (195vA, 205rA, 285vA) / aznalcaçar (195vA, 202vA), estremos (55B) / estremoz (59B) flores (126vA) / florez (de avila) (104rA), mazgallan (116rA) / masgallan (116rA) (Ariza 1994: 226, Ariza 1996: 47). 
Así pues, los únicos casos seguros de seseo-ceceo serían: armençilla (196rA), fortalesa (220vA, 447rA), medina çeli (547rA, 550vA) / medina seli (548vA) - medina oeli (547rA), medina çidonia (205rA, 278rA) / medina sidonia (290rA) - medina oidonia (279vA, 287rA), tordelloço (145rA).

$3^{\circ}$.- Quizá el rasgo de la escritura más característico de los años finales del siglo XV y primeros del XVI sea la sustitución gráfica de la $h$ en las voces que, etimológicamente, tenían F- latina. La modificación a que aludimos, como puede comprenderse, no fue instantánea y como ejemplo de ello en nuestra obra encontramos la alternancia de ambas grafías iniciales; en algunos casos incluso, nos topamos con su ausencia. Con todo, la complejidad del fenómeno deriva de que las vacilaciones gráficas se entremezclan con consideraciones fonéticas puesto que en algunas zonas de la Península aún se mantenía la aspiración del fonema inicial frente a la situación de otras regiones, donde éste había desaparecido (Lapesa 1986: 280, 368; Ariza 1990: 102; Ariza 1996: 58).

La circunstancia que parece estar más directamente relacionada con la preferencia por una u otra grafía en la Descripción... o Itinerario es el tipo de escritura del folio donde el caso aparezca. A grandes rasgos, la escritura humanística -la de Hernando Colón-prefiere la $h$ en los mismos ejemplos en que la escritura medieval gótica- la de los colaboradores emplea $f$.

$4^{\circ}$.- Aunque la desfonologización de la diferencia oclusivo / fricativa entre los fonemas labiales sonoros del castellano medieval se encuentre documentada desde la segunda mitad del siglo XIV, la casos en posición intervocálica -contexto donde, con mayor seguridad, se distinguían los dos fonemas- tomados de la Descripción... o Itinerario demuestran que aún a principios del XVI la diferencia se mantenía ¿sólo gráficamente? (Lapesa 1986: 205-206, 283 y 370-371; Ariza 1990: 160): cabe (244 bis vA), cabeça (31A), lavores de pan (453vA), pasava (33A, 55vA, 279rA), ribadavia (55rA), talaruvias (447rA) -también es cierto que documentamos talarubias (446vA).

$5^{\circ}$.- Se mantiene gráficamente la $b$ implosiva de cabdal (63rA, 314rA, 332rA, 419rA, 484vA, 584vA, 569vA, 574r, 612vA, 652vA), cabtivos (536vA), çibdad (1A, 91vA, 94vA, 187vA, 190rA, 211rA, 300rA, 419vA, 420rA) (Lapesa 1986: 369; Ariza 1990: 93). Es bien sabido que aún Valdés (1987: 168) prefería escribir la $b$ porque "los vocablos están más llenos y mejores con la $b$ que sin ella, y porque toda mi vida los he scrito y pronunciado con b".

Documentamos, asimismo, casos en los que la $b$ implosiva no es etimológica como ocurre en cabsa (247rA, 318rA, 440rA, 473rA, 502rA, 506rA) o en el topónimo sabzedilla (del lat. SALICE) (164rA) en alternancia con sauzedilla (165rA).

$6^{\circ}$.- No se simplifican los grupos consonánticos de nasal más dental en posición final: así lo vemos en el numeral cient (70vA, 286vA) solo o integrando nombres de lugares como cient lavajos (503vA), cient pozuelos (335vA) junto a cienpozuelos (476B) sin $t$ escrito por Hernando Colón; fuent en los topónimos fuent carral (337vA), fuent llana (478vA, 678rA) o fuent santa (588vA) y en alternancia con la forma sin $t$ en casos como fuent çemillan (607rA) / fuen çemillan (611vA) o fuent salida (253rA, 316rA) / fuen salida 
(253vA); y sant en sant agustin (345rA) (Lapesa 1986: 369). Se corresponde, pues, con la respuesta de J. de Valdés (1987: 181) sobre que "muchas vezes he estado en dubda quál tomaría por mejor, y al fin heme determinado en escrivir sin $t$ " a la pregunta de "¿quál es mejor escrivir cien $\sin t$ o cient con $t$ ?".

$7^{\circ}$.- Se reducen los grupos consonánticos de los cultismos en su adaptación, así, en perfeto (16rA) y frutifero (153vA, 539rA, 555vA, 571rA, 582rA) (Lapesa 1986: 280).

$8^{\circ}$.- Alternan en posición final de palabra, por la neutralización de la oposición sordasonora, las grafías de las dentales $-t /-d$. Es reseñable que este rasgo se da especialmente en los folios escritos por Hernando Colón: calatayut (515vA, 556rA, 557vA, 558vA, 560vA, 562rA) frente a un único ejemplo con d (554rA), çibdat (58B, 59B) / çibdad (393B) solo o en el topónimo çibdat rodrigo (68B) / çibdad rodrigo (177r), enbit (556rA) / enbid (556rA), valladolit (4A, 38A, 52rA, 52vA, 53A, 54A, 273rA) / valladolid (4A, 83vA, 332rA, 332vA, 333rA, 368rA, 374rA, 416rA, 418rA, 424vA, 576vA)..

$9^{\circ}$.- Y, por último, parece mantenerse la doble $l l$ etimológica en mill (304rA) y en el artículo determinado ell (Lapesa 1986: 369).

\subsubsection{Morfología (Alvar-Pottier 1987, Lloyd 1993):}

El rasgo más destacable desde el punto de vista de la morfología también es la alternancia, en distinto grado, de formas medievales y de formas modernas.

Así, quedan testimoniadas las del paradigma verbal con los dobletes andovo (251vA) frente a andube (40C) o estove (279vA)- estoviese (226rA) frente a estuve (575rA) cuya vocal tónica en lo antiguo, como bien sabemos, era analógica con la de ovo, forma de pretérito ésta, por lo demás, exclusiva en la obra (213vA, 474rA, 519vA). Similar es, de otro lado, el número de casos que presentan para la primera persona del plural del presente de indicativo del verbo haber avemos (70vA, 38C) y hemos (88rA, 34C). Es muy superior, por el contrario, el número de casos de ymos (110rA, 229vA, 232rA, 242vA, 265vA, 577rA, 652vA, 657vA, 662rA, 667rA, 42C, 65C) en comparación con los de vamos (71rA, 335rA, 577rA, 32vC, 64C).

Fuera de la morfología verbal, se observa una mayor cantidad de ejemplos de alderredor (230vA, 333vA, 350rA, 520rA, 588rA, 606rA, 667vA, 672vA, 48vC, 51vC, $52 \mathrm{vC})$ o enderredor $(612 \mathrm{vA}, 613 \mathrm{vA})$, la preposición cabe $(376 \mathrm{vA}, 425 \mathrm{vA}, 537 \mathrm{rA}, 30 \mathrm{vC})$, ansimismo (64vA, 69rA, 70vA, 74vA, 151vA, 197rA, 210rA, 282rA, 284vA, 286vA, 675vA, 47C), y (entr-)amos (56vA, 71rA, 276vA, 36vC sin preposición; 7A, 182vA, $238 \mathrm{vA}, 585 \mathrm{vA}, 1 \mathrm{C}$ con preposición), en contraste con sus "sustitutos" alrededor (304rA, 346rA, 413rA, 591vA), junto (304r), asi (430vA, asymismo en 464rA), y (entr-) anbos (7A, $657 \mathrm{rA}, 13 \mathrm{vC}, 14 \mathrm{vC}$ sin preposición y $609 \mathrm{vA}$ con preposición).

Por último, documentamos de manera esporádica la pervivencia de:

$1^{\circ}$.- Do junto a donde: "hasta la villa do ay una grande puente" (58rA). Do era frecuente aún a finales del siglo $\mathrm{XV}$, pero poco después la encontramos sólo en el lenguaje poético y en el estilo elevado o arcaizante. 
$2^{\circ}$.- Las preposiciones des o dende frente a desde: "nuestra señora vino en proçesyon dende santa maria la mayor" (590rA), "todas estas villas e lugares que hemos dicho des motrico hasta fuente rabia" (34C). Des es la más antigua, resultado, como es bien sabido, de la unión de las preposiciones latinas DE y EX. A partir de ella, por adición de otra de, se formó desde. Dende, por su parte, resulta de la combinación de desde con desende con el valor de 'desde entonces'; empleada por Nebrija, Valdés sólo la admite en la poesía. En contraste con la opinión de Corominas-Pascual, según la cual dende "vulgarmente se confundió con desde", dos de las tres veces que la leemos en la Descripción... o Itinerario son obra de Hernando Colón, hombre que, por lo que sabemos, no era precisamente vulgar.

$3^{\circ}$.- El pronombre vos en función de objeto (único ejemplo): "yo vos mando" (482vA).

$4^{\circ}$.- La preposición so: "burgos [...] esta en la yglesia mayor so el sacramento el cuerpo de san garçia que lo mataron los judios en la cuesta de santa $\mathrm{m}^{\mathrm{a}}$ la blanca" (53A). Frecuente durante la Edad Media, decayó por razones fonéticas frente a su sustituto debaxo. Su empleo desde el XVI se restringe ante un grupo muy reducido de sustantivos (pena, pretexto...).

$5^{\circ}$.- El demostrativo reforzado por otro (Alvar-Pottier 1987: 108). La forma resultante estotro, frecuente en la época medieval, aún se emplea en el siglo XVI (Lapesa 1986: 397). En la obra posee el significado de 'siguiente' (dice Keniston 1938: 214: "with a noun of time, estotro may have the force of "next"') (de cinco casos documentados, cuatro corresponden a Hernando Colón: 674vA, 222B, 302B, 338B, 504B).

En otro orden de cosas, los tres sufijos diminutivos del castellano medieval (-illo, -ejo, -uelo; vid. González Ollé 1962) siguen siendo en la Descripción... o Itinerario los más frecuentes (cabría preguntarse si lexicalizados en unos mismos sustantivos): barranquillos (449vA), çerrillo (365vA, 379vA), montezillo (79rA, 384rA), leguachuela (55vA), peñuela (520rA, 570rA), serrezuela (213rA, 242vA, 265vA, 418rA, 477rA, 655rA, 360B), carrascalejo (423rA), castillejo (570rA, 575rA), lugarejo (49A, 427rA, 571vA, 654vA). Aparecen aún pocas veces los sufijos -ito o -ico en contextos donde "correspondían" los precitados. Los ejemplos de este último son, en cualquier caso, más abundantes y así tenemos cerrico $(1 \mathrm{vC}, 17 \mathrm{vC})$, pequeñica $(157 \mathrm{vA}, 282 \mathrm{vA}, 344 \mathrm{rA}, 459 \mathrm{vA}, 677 \mathrm{vA})$, portezico $(30 \mathrm{vC})$, subidica $(18 \mathrm{r})$, vallezico $(10 \mathrm{vC}, 11 \mathrm{vC}, 14 \mathrm{C})$, frente a un único caso de chiquitas (55rA) y otro de chiquito (19C).

\subsubsection{Sintaxis:}

$1^{\circ}$.- El verbo aver aparece expresando tiempo en construcciones del tipo "villanueva de fuente el frexno [...] avra XX años que se poblo" (342rA) o en "antequera [...] ha C años que se tomo (49C)". Sólo en un caso: "aviendo gran sed" (59rA), cuyo responsable es Hernando Colón, funciona como verbo transitivo de posesión, pues ya parece haberse generalizado tener para tal empleo (Seifert 1930).

$2^{\circ}$.- Ser sirve para expresar lugar cuando el complemento locativo que le acompaña hace referencia a una zona de extensión variable (desde un reino a una comarca) acompañada de su nombre propio: "es en galizia" (66vA), "es en el reyno de toledo" (77rA), "es en el condado de ñebla" (197vA). Estar, por el contrario, lo encontramos cuando el complemento 
de lugar consta sólo de un apelativo o la situación que expresa es de tipo genérico: "esta en un valle" (24rA), "esta en una ladera" (480rA). Puede comprobarse la alternancia entre estar y ser en pasajes del tipo: "esta en llano [...] e es riberas de guadiana" (166rA), "altamyra es en galizia [...] e esta en alto" (188vA). En cualquier caso, el esquema trazado presenta algunas excepciones, y así, leemos "esta en la huerta de murçia" (669rA, 677rA) o "esta en la sierra morena" (191rA, 312rA), aunque también tenemos "es en la sierra morena" (191rA, 467vA, 605rA). Los complementos de lugar que parecen sujetarse menos a la "regla" son los que, sin preposición, están integrados por sustantivos del tipo riberas, orilla más un sintagma nominal que incluye un nombre propio. Según lo esperable, deberían darse con ser y observamos cómo su frecuencia es mayor con estar.

$3^{\circ}$.- Es conocido cómo, quizá por influjo culto y latinizante, se recuperó en el siglo XV el empleo verbal del participio de presente -en lugar de gerundio o de subordinada de relativo. Pues bien, este rasgo de la sintaxis de ese siglo aún permanece en el "español preclásico" (Lapesa 1986: 268, 277; Cano 1993: 187), muestra de lo cual es el siguiente caso de nuestra obra: "fasta orgaz ay una legua grande la media primera es de puerto travesante un çerro" (248vA).

$4^{\circ}$.- Las perífrasis de contenido inceptivo presentan como índice preposicional de, en ninguna ocasión $a$ (Cano 1977: 369-370): "enpieça de aver" (652vA), "encomiença de salir debaxo de tierra" (322rA).

$5^{\circ}$.- Las oraciones subordinadas temporales de posterioridad son introducidas por de que. Esta conjunción está documentada desde los orígenes de la lengua literaria hasta, precisamente, la primera mitad del XVI, fecha desde la que subsistirá "en el lenguaje familiar" (Eberenz 1982: 331, 378): "de que llegamos al lugar se abaxa una cuesta que tenra tiro e medio de vallesta" (69vA), "de que salimos de fuente el puerco abaxamos una cuesta que tenra un tiro de vallesta" (89rA), "de que llegan al lugar dexan el rio a la dizquierda" $(39 \mathrm{vC})$. También hemos extraído un caso de cada que, poco abundante ya en el siglo XV y cuyo contenido era de coincidencia iterativa: "un atalaya [...] dicho menzui de donde hazen seña cada que viene navio" (575rA). Fue sustituida por cada vez que o siempre que en el siglo XVI (Méndez 1995: 153-154). Recordemos, al respecto, la afirmación de J. de Valdés "cada que por siempre dizen algunos, pero no lo tengo por bueno".

2.1.4. Por último, también en el léxico hay que destacar la documentación de lexemas con acepciones o formas propias del castellano de la Edad Media:

Anchor (no tiene este puerto mas anchor que quanto pasa xalon rio: 556vA, 181B). Es forma anticuada que concurría con la de su mismo significado anchura. Anchor aún aparece en el vocabulario de Palencia.

Bulto (Sicuendes [...] en este lugar mataron syete condes por donde se llaman sycuendes e ay bultos de yelso dellos: 505rA). La voz mantuvo su acepción originaria hasta el siglo XV con algún que otro caso documentado en el siglo siguiente a decir de Corominas y Pascual. En nuestro ejemplo, bulto se refiere a las imágenes que representan la 
cabezas de santos o a las estatuas que figuraban de relieve el cuerpo de una persona en las sepulturas.

Calnado (Laredo [...] se pueden poner dentro dozientas naos que se pueden çerrar todas con un calnado: 70rA). Aparece en muchas obras literarias medievales según Corominas y Pascual. Aún a principios del XVII S. de Covarrubias dice de candado que "corruptamente le llaman calnado".

Defensyon (ocaña [...] tiene una torre de defensyon: 27C). Defensyon es derivado más antiguo y culto que defensa, forma ésta testimoniada sólo desde fines del siglo XV según Corominas y Pascual.

Derrocar (junto con el camino esta un castillo antiguo derrocado: 499vA). Muy frecuente en la Edad Media en concurrencia con derrumbar, derribar-- Antonio de Nebrija dice de derrocar que es "lo mesmo que derribar"-- o despeñar. Su entrada en castellano "como expresión militar, se vio determinada por el gusto de los caballeros por imitar la fraseología de origen catalán y occitano, donde tal expresión era antigua y usual" en palabras de Corominas y Pascual.

Ledanias (Sicuendes [...] bienen çinco cruzes de lugares al tiempo de las ledanias en proçesjon: 505rA). En esa forma, con -T- entre vocales sonorizada, está testimoniada desde Berceo. La variante letanías con t sólo se constata a fines del XV --Corominas y Pascual citan a Nebrija.

Meatad (pasase arnoya por la ponte frexo a la meatad del camino: 9rA). Según Menéndez Pidal (1999: 265-270) es la forma predominante en el siglo XIII.

Miraglo (esta un cruçifixo en esta çibdad en la trinidad que ymita al que mas perfeto fue de nicodemus \& faze ynfinitos miraglos: 16rA). En otra ocasión, además de la citada, puede leerse esta forma en contraste con milagro que es mucho más abundante en la obra. Con todo, según Corominas y Pascual (s.v. mirar), miraglo todavía es admitida en el siglo XVI.

Xara (vase por una xara denzinas: 201B, 17vC), significando 'bosque'. Con la acepción moderna, en referencia a un tipo determinado de planta, no se documenta antes de Antonio de Nebrija.

Ynestar (fasta cariñena ay IV leguas de tierra llana e de montes de ynestares: 563rA), derivado de hiniesta que, según M. Ariza (1997: 65), "debió dejar de usarse a fines de la Edad Media, pues ya Nebrija la define a partir de retama y no la encuentro en escritores del Siglo de Oro". Como sabemos, hiniesta fue progresivamente sustituida por el arabismo retama.

3. En definitiva, tal como decíamos al principio, el análisis de la lengua de la Descripción... o Itinerario (vid. 2.), lejos de rectificar los planteamientos que sirven a los historiadores de la lengua para caracterizar al llamado "español preclásico" (vid. 1.), período "bisagra" entre el castellano medieval y el español clásico, demuestra que aún pervivían numerosos rasgos lingüísticos medievales en lo que fueron sus años finales. 


\section{BIBLIOGRAFÍA:}

E. Alarcos, Fonología española (Madrid 19864).

E. Alarcos, "De nuevo sobre los cambios fonéticos del siglo XVI", Actas del I Congreso Internacional de Historia de la Lengua Española I (1988) 47-59.

M. Alvar-B. Pottier, Morfología histórica del español (Madrid 1987).

M. Ariza, Manual de fonología histórica del español (Madrid 1990).

M. Ariza, "La Descripción y Cosmografía de España, de Hernando Colón (Aspectos lingüísticos)", Antiqua et nova Romania (Estudios lingüísticos y filológicos en honor de José Mondéjar en su sexagésimo aniversario) I (Granada 1993) 19-26.

M. Ariza, Sobre fonética histórica del español (Madrid 1994).

M. Ariza, "Reflexiones sobre la evolución del sistema consonántico en los Siglos de Oro", Actas del III Congreso Internacional de Historia de la Lengua Española I (1996) 43-80.

M. Ariza, "Historia lingüística del andaluz", Las hablas andaluzas. Demófilo 22 (1997) 5968.

M. Ariza, "Fernando III y el castellano alfonsî", Estudios de lingüística y filología españolas. Homenaje a Germán Colón (Madrid 1998) 71-84.

R. Cano, "Cambios de construcción de los verbos en castellano medieval", Archivum XXVII-XXVIII (1977) 335-379.

R. Cano, "La sintaxis española en la época del Descubrimiento", Estudios filológicos en homenaje a Eugenio de Bustos I (1993) 183-197.

R. Cano, "Los Orígenes del español: Nuevos planteamientos", Estudios de lingüística y filología españolas. Homenaje de Germán Colón (Madrid 1998) 127-140.

J. Corominas-J. A. Pascual, Diccionario crítico etimológico castellano e hispánico (Madrid 1980-1991).

S. de Covarrubias, Tesoro de la lengua castellana o española (1993 Barcelona).

R. Eberenz, "Las conjunciones temporales del español. Esbozo del sistema actual y de la trayectoria histórica en la norma peninsular”, BRAE LXII (1982) 289-384.

R. Eberenz, "Castellano antiguo y español moderno: Reflexiones sobre la periodización en la historia de la lengua", RFE LXXI (1991) 79-106.

M. García Blanco, La lengua española en la época de Carlos V (Santander 1958).

F. González Ollé, Los sufijos diminutivos en castellano medieval (Madrid 1962).

J. Guillén, "Hernando Colón”, Isidorianum 2 (1992) 185-221.

R. Lapesa, Historia de la lengua española (Madrid 1986 ${ }^{6}$ ). 
P. M. Lloyd, Del latín al español I. Fonología y morfología históricas de la lengua española (Madrid 1993).

T. Marín, Obras y libros de Hernando Colón (Madrid-Sevilla 1970).

E. Martinet, Economía de los cambios fonéticos (Madrid 1974).

E. Méndez, Las oraciones temporales en castellano medieval (Sevilla 1995).

R. Menéndez Pidal, "El lenguaje del siglo XVI", La lengua de Cristóbal Colón (Madrid 1978) 47-84.

R. Menéndez Pidal, Orígenes del español (Madrid 1999 ${ }^{11}$ ).

A. de Nebrija, Vocabulario Español-Latino (Madrid 1951).

E. Ridruejo, “¿Un reajuste sintáctico en el español de los siglos XV y XVI?”, Actas del Primer Congreso Anglo-Hispano I (1994) 49-60.

E. Seifert, "Haber y tener como expresión de la posesión en español", RFE XVII (1930) 233-276, 345-389.

J. de Valdés, Diálogo de la lengua (Madrid 1987).

K. Wagner, "Hernando Colón: semblanza de un bibliófilo y de su biblioteca en el quinientos aniversario de su nacimiento", El libro antiguo español. Actas del Segundo Coloquio Internacional (1992) 475-492. 
